Research Article

\title{
Torsional Stiffness Correction of the Split-Type Triple-Box Steel Box Girder Based on Refined Simulation
}

\author{
Yu Tang, ${ }^{1}$ Min Xu ${ }^{D},{ }^{1}$ Jie Yue, ${ }^{1}$ and Shixiong Zheng ${ }^{2}$ \\ ${ }^{1}$ School of Civil Engineering and Geomatics, Southwest Petroleum University, Chengdu 610500, China \\ ${ }^{2}$ School of Civil Engineering, Southwest Jiaotong University, Chengdu 610031, China \\ Correspondence should be addressed to Min Xu; minzihaha2@163.com
}

Received 20 April 2021; Revised 6 June 2021; Accepted 21 June 2021; Published 29 June 2021

Academic Editor: Payam Shafigh

Copyright $(02021 \mathrm{Yu}$ Tang et al. This is an open access article distributed under the Creative Commons Attribution License, which permits unrestricted use, distribution, and reproduction in any medium, provided the original work is properly cited.

Split-type steel box girders are widely used in long-span bridges because of their good wind-resistance performance. In the design stage, a simple finite element model is usually established based on the beam element for wind-resistance design. However, since the irregular cross-beams and diaphragms in the split steel box girder cannot be virtually established, the stiffness of the girder will be underestimated. To improve the accuracy in simulating stiffness of the split-type triple-box steel box girder (STSBG) with the beam element model (BEM), a correction is made to the initial beam element model (IBEM) based on the result of a more refined finite element model. ANSYS is adopted to make a refined model (RM) of a bridge with STSBG as its girder and to calculate its aerostatic responses and dynamic characteristics in 3 typical construction states and 1 finished state. With the reference value, an objective function of the overall residual sum of squares is constructed for the torsion angle of the girder and the frequency of the bridge. Then, the beam element is used for conventional modelling of the bridge, and artificial bee colony (ABC) algorithm is adopted for the optimization and correction of structure parameters of the BEM of the girder. Finally, static and dynamic characteristics of the IBEM and the corrected beam element model (CBEM) are compared with values of the corresponding RM to evaluate the validity of the correction of the model. The results show that the aerostatic responses and dynamic characteristics of the CBEM are close to calculated values of the RM. In more detail, the relative error between the torsion angle of the girder in the middle span of the BEM and the corresponding reference value in the finished state is decreased from $+61.71 \%$ to $+4.94 \%$, and the relative error of torsional fundamental frequency is decreased from $-17.43 \%$ to $+3.66 \%$. According to the calculated value of the $\mathrm{RM}, \mathrm{ABC}$ algorithm would satisfactorily improve the accuracy in simulating torsional stiffness of the STSBG with the IBEM. This research is expected to provide reference for beam element modelling, which is conducive to accurately simulating torsional stiffness of the STSBG

\section{Introduction}

It is common that the finite element model of the long-span bridge is built by simulating girder or member based on onedimensional two-node beam elements. In the construction of such a bridge, closed steel box girder is widely applied by virtue of its light weight, fast construction speed, and good aerodynamic performance. When using beam element to build model for single-box steel girder, single-girder, double-girder, and triple-girder are adopted [1]. However, due to the complicated section-shape and the diaphragms inside the box girder, it is difficult to calculate the torsional stiffness. Kang et al. [2] developed the corresponding calculation program based on the calculation theory of shear flow in the thin-walled cross sections and calculated the free torsion constant of arbitrary complicated thin-walled cross sections. Another approach was also introduced to exactly determine both the torsional constant and all shear flows for multicell cross sections under torsion [3]. Xu et al. [4] summarized a method to calculate the geometric parameters of the cross section of thin-walled box girder with the help of spatial finite element analysis software. Although these softwareassisted methods for calculating the geometric features of the girder cross section were simple, they cannot directly simulate the intermediate diaphragms inside the box girder. Zhang and Ge [5] took Jiangyin Yangtze River Bridge as an 
engineering object to establish a BEM and a shell element model for dynamic analysis, and they found that the antisymmetric torsional frequency of the first order of the girder has a discrepancy of $10.25 \%$, and the antisymmetric transverse bending frequency of the first order has a discrepancy of $17.75 \%$. Chen [6] deduced the theoretical formula of torsional stiffness of orthotropic deck steel box girder. Taking the standard section of Runyang Bridge as an example, he also demonstrated that the U-shaped rib of orthotropic deck steel box girder could improve the torsional stiffness by about $5 \%$. As per the finite element simulation results of Zhang and Chen, the U-shaped ribs and intermediate diaphragms could not be directly simulated by the IBEM, because, in that way, it would result in an underestimation of the torsional stiffness of steel box girder, thus inducing a certain difference between the static and dynamic characteristics of the bridge and the real value of the actual structure.

When the span of long-span bridges is increased, the aerodynamic stability of the bridges with closed steel box girders would be impaired. Therefore, a new girder structure, the split steel box girder, with better flutter performance was innovated. Currently, the split steel box girder is divided into the split-type double-box steel box girder (SDSBG) and STSBG. Tsing Lung Bridge in Hong Kong, China, is one of the earliest bridges designed with the SDSBG [7], while Strait of Messina Bridge is one of the earlier bridges designed with the STSBG [8]. Since there are increasing bridges designed with the split steel box girder as the girder, some scholars have conducted numerical and experimental study on the torsional stiffness of split steel box girder. Li [9] established the cantilever beam model of shell element and beam element with a SDSBG and thought that the beam element segment model could not accurately reflect the real torsional deformation of split steel box girder. Meanwhile, he established IBEM of the bridge and found that there were some differences between the torsion angle of the girder and the measured value of the bridge model test. Li et al. [10] established the IBEM of a suspension bridge with the SDSBG as the girder, and the calculation results showed that, during the construction stage, the flutter stability would decrease with the reduction in the torsional stiffness of the girder. This indicates that increasing torsional stiffness of girder can improve the flutter performance [11] and suppress the buffeting displacement [12]. The conventional IBEM cannot virtually simulate the cross-beams and the intermediate diaphragms inside the box of the SDSBG, because, in that way, it would result in underestimation of the real torsional stiffness of the girder. But the flutter stability of the bridge is closely related to the torsional stiffness of the girder [13]. From the above, it can be easily seen that it is of great significance to establish the finite element model accurately.

At the same time, many scholars have done a lot of researches on the improvement of torsional stiffness of girder. Bottom bracing systems can be added in curved girder bridge design to improve their dynamic characteristics [14]. For the long-span bridge, when two lateral steel beams are added to the middle span of the structure [15], or when the central buckle is settled [16], the bending and torsional stiffness of the structure and the deck driving safety can be increased to a large extent. These methods can enhance the torsional stiffness of the girder, thus improving the stability and safety of the structure. Also, by changing the form of cable frames $[17,18]$ and adjusting vertical interval and numbers of cable frames [19], some scholars have improved the stiffness of the structure, reduced vibration, and strengthened the dynamic behavior of the bridge. However, these methods increase the stability of the bridge structure merely at a higher cost and do not really solve the problem that the torsional stiffness simulation of the girder is distorted when the bridge structure is simulated by the IBEM. It is crucial to employ the above-mentioned method to improve the structural stiffness, and it is also essential to accurately simulate the bridge structural stiffness, both of which lay a solid foundation for the wind-resistance or antiseismic [20] work in the later stage.

In the wind-resistance design of long-span bridges, it is very important to analyze aerostatic stability and flutter stability. Typical aerostatic instability is the so-called torsional divergence, which may give rise to abrupt structural failure [21]. The related checking contents of what should be verified involves whether the critical wind speeds of aerostatic instability and flutter of bridges meet the code requirements. The calculation of both critical wind speeds is directly related to the torsional fundamental frequency of the girder. If the torsional stiffness of the girder is underestimated, the fundamental torsional frequency of the girder will be underestimated, thus resulting in the underestimation of the critical wind speed. At this time, to make both checking calculations of wind-resistance approved, additional measures (such as improving the stiffness of the structural system, adding aerodynamic measures, or adding dampers) should be taken in the design of bridges, which would increase the construction cost of the bridge project. For super-long-span bridges, the increase of engineering cost and the decrease of design economy caused by the failure in the wind-resistance design may be one of the key factors to decide which bridge scheme is to be selected. Therefore, it is of great significance to accurately simulate the torsional stiffness of the split steel box girder. Shell element can well simulate the steel bridge structure composed of steel slab elements [22], and the torsional stiffness of the girder can be obtained by establishing a RM.

At present, studies of the torsional stiffness of STSBG have not yet been reported. Previous studies mainly focused on the influence of changes of parameters on the dynamic characteristics of bridges and some methods to improve the torsional stiffness of structures but failed to fundamentally solve the problem of BEM simulation accuracy of such steel box girders. To simulate the torsional stiffness of such steel box girders more accurately, this paper uses a cable-stayed suspension bridge with STSBG as the engineering background to build a RM to study the torsional stiffness of the girder; meanwhile, it uses this as the reference value to correct the torsional stiffness of the IBEM by using an ABC algorithm. RM can accurately simulate the performance of the girder structure, and $\mathrm{ABC}$ algorithm can quickly and accurately correct the stiffness of the girder of IBEM, so that 
CBEM can replace RM for subsequent simulation calculation.

\section{Torsional Stiffness Calculation Theory of the Beam}

The torsional stiffness of a beam is codetermined by its elastic modulus and the form of geometric cross sections. Figure 1(a) shows common round straight beams in the pile foundation engineering of bridges. For the same material, $G$ and $I_{p}$ are constants. $G$ is the shear modulus, and $I_{p}$ is the polar moment of inertia [23], and the torsional stiffness can be calculated by the following formula:

$$
G I_{p}=\frac{T l}{\varphi},
$$

where $G I_{p}$ is the torsional stiffness of round straight beams, $T$ is the torque, $l$ is the length of the beam, and $\varphi$ is the relative torsion angle between both ends of a beam.

When analyzing the stress on the torsional cross section of round straight beam, it is necessary to rely on its assumption of plane cross section. However, when analyzing nonround straight beam, the cross section of the beam is no longer flat after torsion. Therefore, the formula for the torsion of round straight beam is not applicable to the torsion of nonround straight beam. In the design of bridge, common rectangular beams are particularly popular. As shown in Figure 1(b), the torsion angle per unit length of rectangular cross-section beam can be calculated by the following formula:

$$
\varphi^{\prime}=\frac{T}{G I_{t}},
$$

where $I_{t}$ is the equivalent polar moment of inertia of the cross section, which is calculated by the following formula:

$$
I_{t}=\beta h b^{3},
$$

where $\beta$ can be found in [23], and its value varies with the ratio of the size of the long and short sides of the rectangular cross section.

Some thin-walled cross-section components are commonly used in the design of bridge, including open thinwalled cross sections and closed thin-walled cross sections. The centerline of the wall thickness of open thin-walled cross sections is an unclosed broken line or curve, such as the T-shape in Figure 1(c), and the equivalent polar moment of inertia of the entire cross section can be calculated by the following formula:

$$
I_{t}=\frac{1}{3} \sum_{i=1}^{n} h_{i} \delta_{i}^{3} .
$$

As for closed thin-walled cross-section components, the centerline of the wall thickness is a closed broken line or curve, as shown in Figure 1(d). The torsion angle per unit length of a long straight component with closed thin-walled cross sections can be obtained according to the functional principle. As per derivation and analysis, when the wall thickness is a constant, it can be calculated by the following formula:

$$
\varphi^{\prime}=\frac{T s}{4 G A_{0}^{2} \delta},
$$

where $s$ is the total length of the centerline of the wall thickness, $A_{0}$ is the area enclosed by the centerline, and $\delta$ is the wall thickness.

The cross section of closed thin-walled box girder is often designed as a single box with multichambers, and the torsional constant of the cross section can be calculated by the following formula [4]:

$$
K=4 \sum_{i=1}^{n} \bar{q}_{1} F_{i},
$$

where $K$ is the torsional constant, $\overline{q_{l}}$ is the shear flow in each chamber, and $F_{i}$ is the area enclosed by the periphery of chamber $i$.

If there are numerous chambers in the cross section of steel box girder, it is more complicated to solve the shear flow in each chamber. The torsional stiffness of the singlebox girder can be calculated by the existing analytical formula. If the calculation of the cross section of complex steel box girders is cumbersome in actual operation, it can also be obtained by reading the cross section with the aid of finite element software.

When the girder is a split steel box girder (as shown in Figure 1(e)), if the girder is modelled as a single-girder, its torsional stiffness cannot be expressed by the above analytical formula, on the ground that it is difficult to obtain the analytical expression of torsional strain energy of the whole girder based on the assumption of pure torsion of the cross section due to the existence of the cross-beams. If the multigirder modelling method is employed, the torsional stiffness of each steel box can be calculated by the above analytical formula (or by reading the cross section with the aid of finite element software), but the irregular cross-beams and the diaphragms inside the box cannot be virtually simulated, because, in that way, it will result in the distortion of the overall torsional stiffness simulation of the girder to a certain extent. Therefore, it is necessary to correct the model accordingly. It is of practical significance to use the calculation results of the more refined shell element model as a reference value at the design stage to correct the parameters of the IBEM to achieve equivalence between the two in terms of static and dynamic performance.

\section{Engineering Background}

Figure 2(a) presents a bridge of $2664 \mathrm{~m}$ with two towers and three spans, whose main span is $1488 \mathrm{~m}$. Figure 2(b) shows a STSBG, which is $5 \mathrm{~m}$ in height and $68 \mathrm{~m}$ in width, with highway box girder on both sides and a railway box girder in the middle. And an intermediate diaphragm is arranged every $2.8 \mathrm{~m}$ in the longitudinal direction inside the box girder, namely, 2892 in total in the whole main bridge. The box girders are connected by cross-beams, which are placed every $14 \mathrm{~m}$ in the longitudinal direction, namely, 382 in total. 


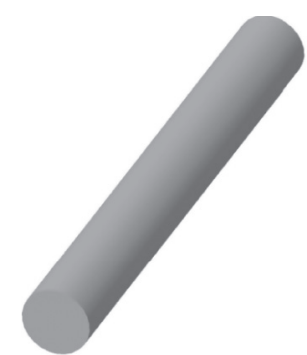

(a)

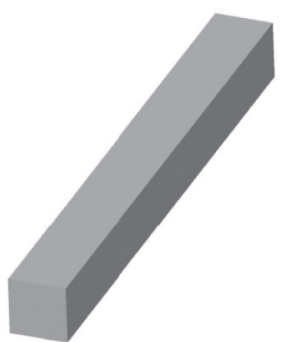

(b)

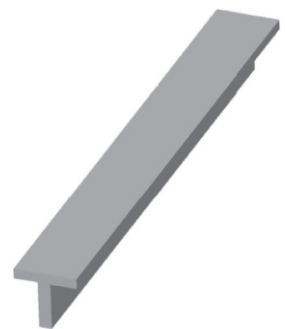

(c)

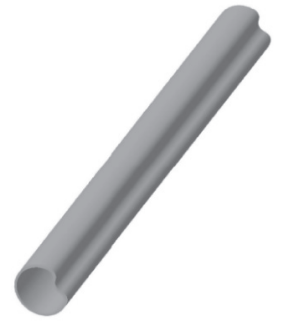

(d)

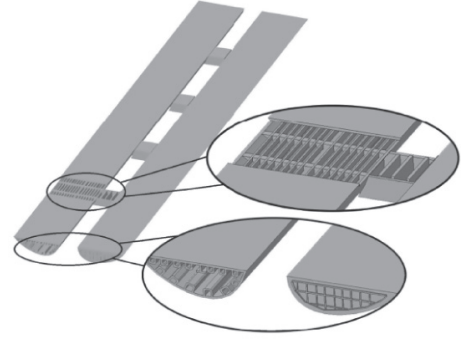

(e)

FIgURE 1: Straight beam with different cross-section forms.

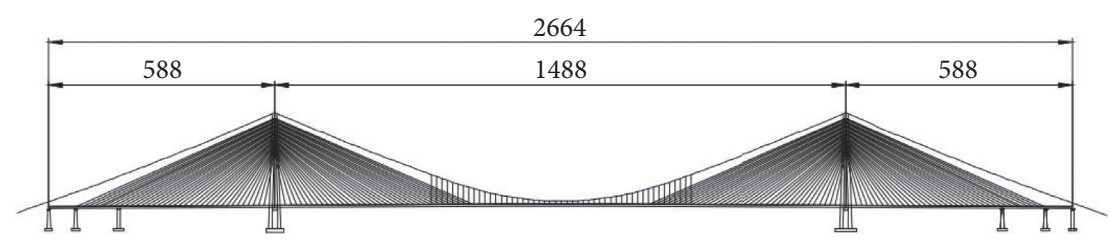

(a)

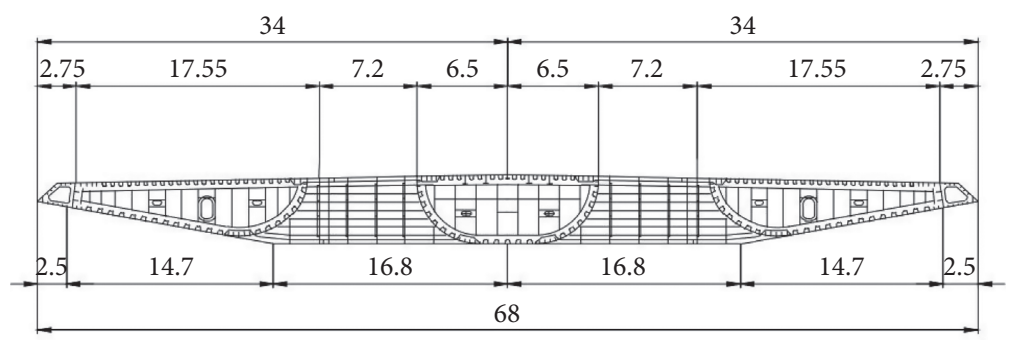

(b)

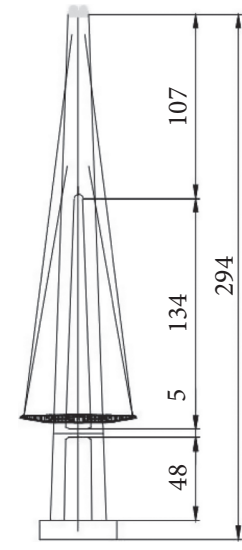

(c)

FIgURE 2: Bridge layout (unit in $\mathrm{m}$ ). (a) Elevation layout of the main bridge. (b) Cross section of the girder. (c) Elevation layout of the bridge tower.

As shown in Figure 2(c), the bridge tower is a $294 \mathrm{~m}$ reinforced concrete structure. Stay-cable tension and concentration points are set every $2.5 \mathrm{~m}$ from the top of the tower to the middle, with 36 points in total. The stay-cables are arranged in a fan shape of a dense cable system, with a total of 288 stay-cables in the whole bridge. The main cable is a spatial cable, and the distance between the two main cables gradually changes. A pair of suspension cables are arranged every $14 \mathrm{~m}$ in the longitudinal direction, with 98 suspension cables in total.

\section{Finite Element Modelling and Fundamental Frequency Differences}

4.1. Finite Element Modelling. The finite element analysis software ANSYS is adopted to establish the IBEMs. The girder is simulated by BEAM44 element, as shown in Figure 3(a), and geometric characteristics of each girder and cross-beam are obtained by reading the cross section with the aid of finite element software. The bridge tower is simulated by BEAM44 element. Stay cables, main cables, and suspension cables are simulated by LINK10 element. The second deck dead load and intermediate diaphragms are simplified as additional mass, simulated by MASS21 element, and distributed to each girder node in view of the moment of inertia.

The IBEMs of typical construction stages (the common double-cantilever state, the longest double-cantilever state, and the preclosure states) and the finished state are established by compiling command stream, as shown in Figure 4, in which the IBEM in the finished state includes 2809 nodes and 4159 elements.

Meanwhile, the RMs corresponding to the IBEMs are established, as shown in Figure 4. The girder is simulated by SHELL181 element. And the top slab, bottom slab, intermediate diaphragms, and stiffening rib of the steel box 


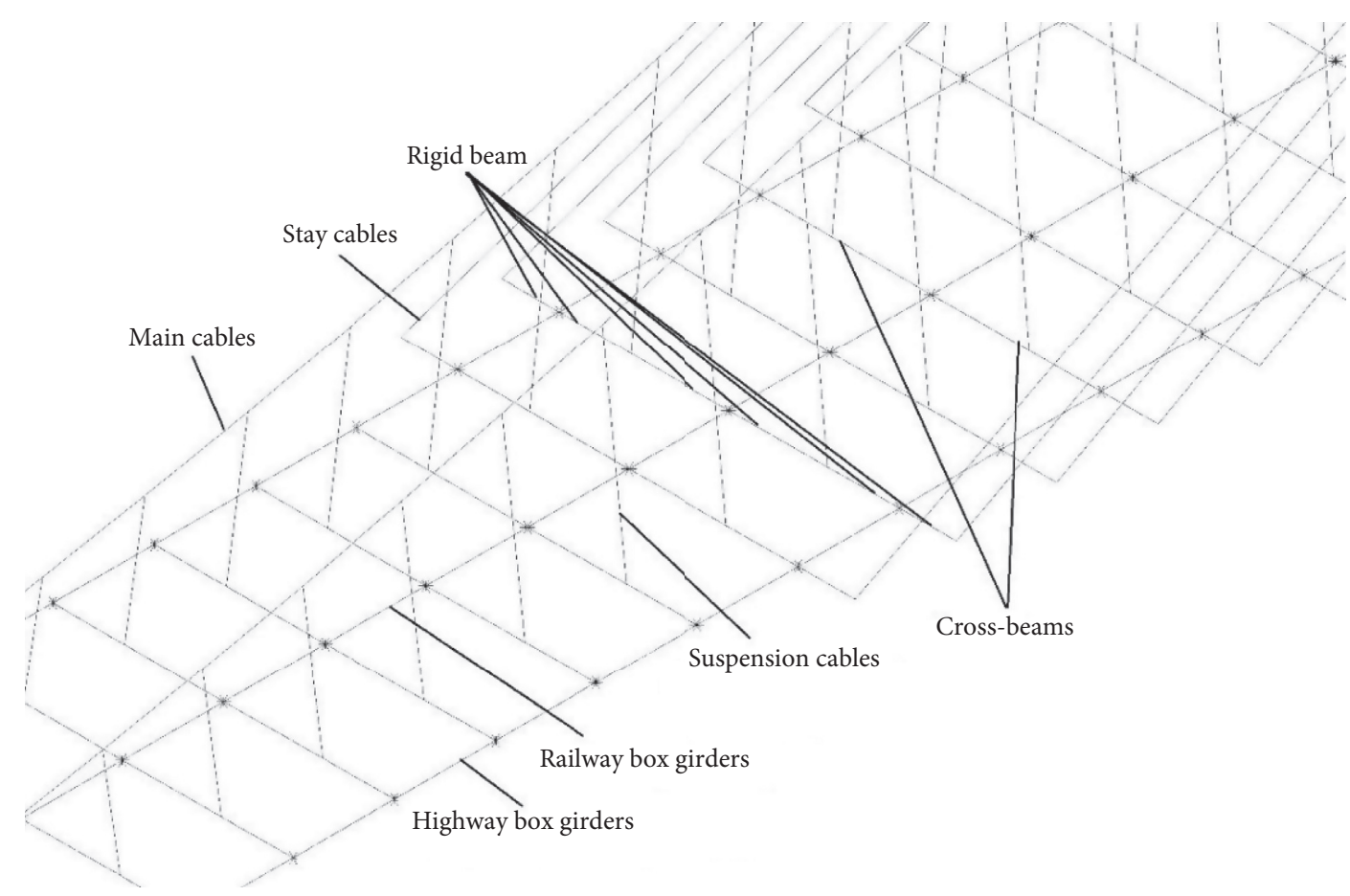

(a)

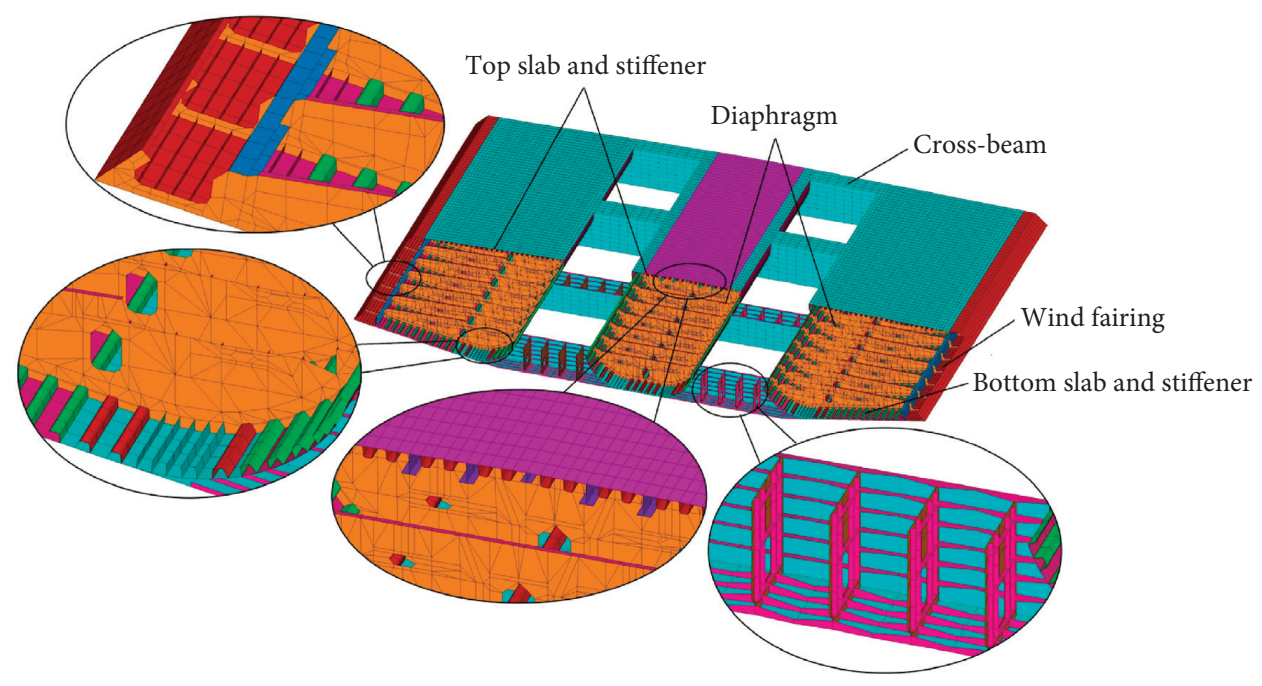

(b)

FIgURE 3: Local construction diagram. (a) IBEM. (b) RM.

girder and cross-beams are divided into several shell elements for accurate simulation, as shown in Figure 3(b). The bridge tower is simulated by the selection of the 8 -node SOLID185 element. The simulation element and modelling method of stay-cables, main cables, suspension cables, and the second deck dead load are identical to those of the IBEM. But the cable end anchorage at the joint of staycables, suspension cables, and girder cannot be directly simulated, so a rigid area is set for the simulation. The RM in the finished state includes 5,029,138 nodes and 5,953,325 elements.

According to the design drawings, the material properties of the bridge are shown in Table 1.
In the finished state, the girder restricts the vertical and transverse displacement at the bridge pier to serve as the bearing, as well as the transverse displacement at the intersection of the tower and girder. The bottom of the bridge tower and the anchor end of the main cable are fixed. There is no constraint in the longitudinal direction of the whole bridge. The girder in each construction state is consolidated at the intersection of the tower and girder to serve as the provisional bearing. Through geometric form-finding analysis, the alignment of main cable and girder under dead load is consistent with the designed alignment, and the subsequent analysis of aerostatic responses and dynamic characteristics is also based on these models. In the 
IBEM

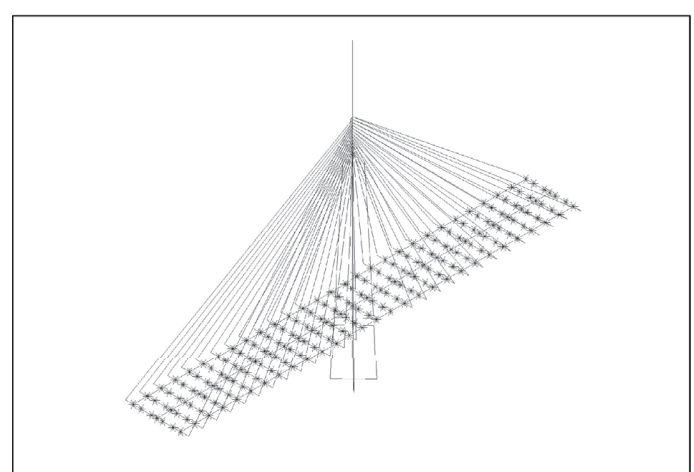

IBEM

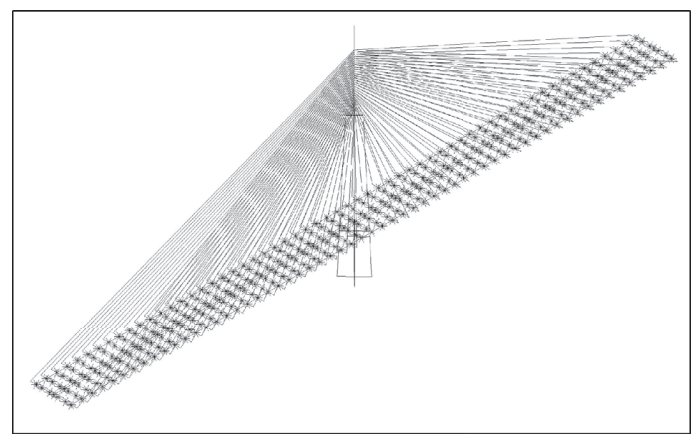

IBEM

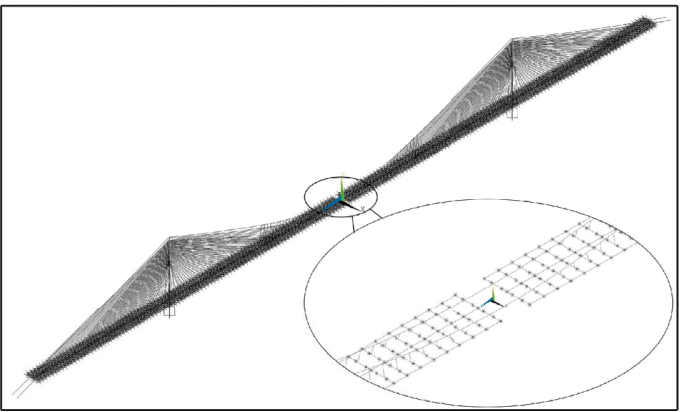

IBEM

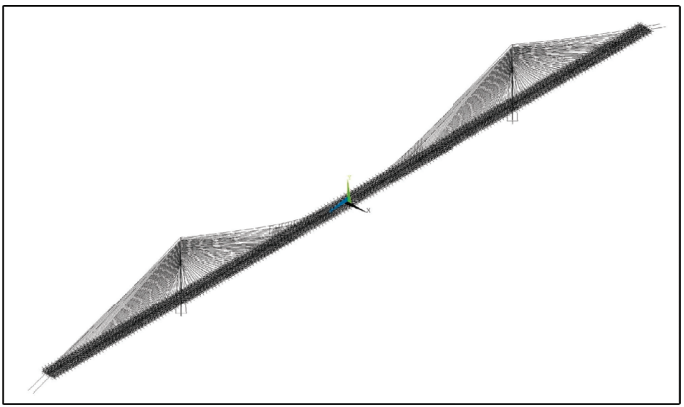

RM

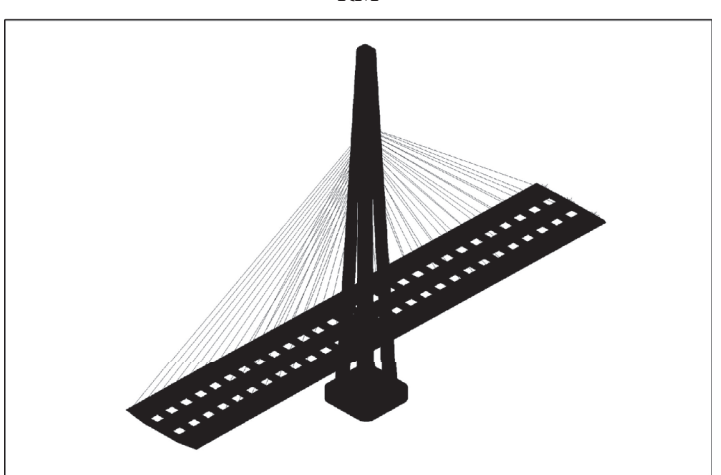

(a)

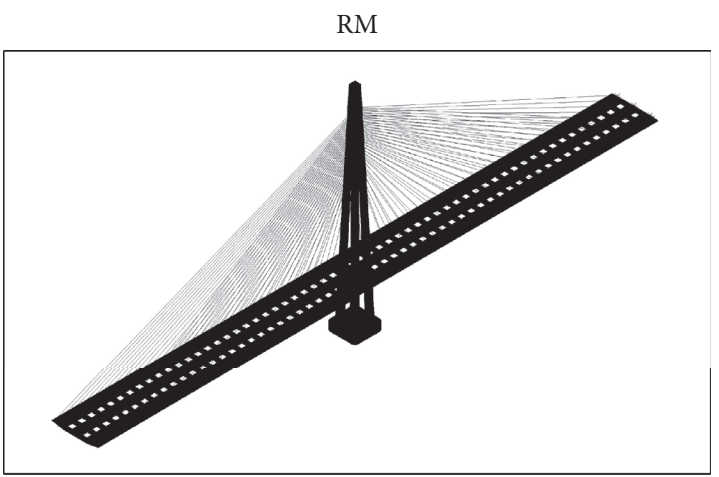

(b)

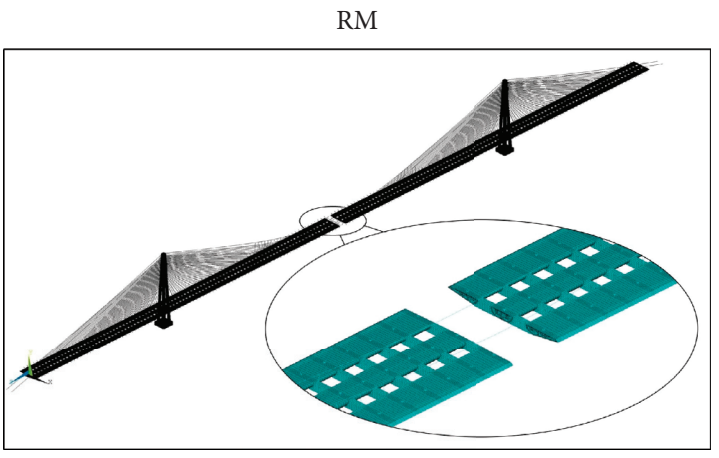

(c)

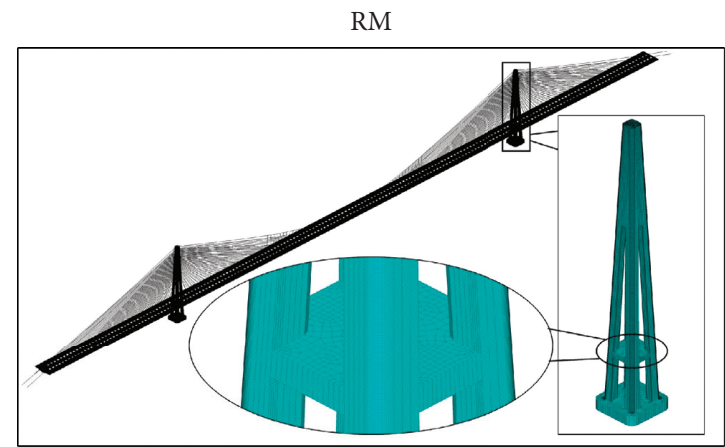

(d)

Figure 4: Finite element models in different stages. (a) The common double-cantilever state. (b) The longest double-cantilever state. (c) The preclosure states. (d) The finished state. 
TABLE 1: Material properties.

\begin{tabular}{|c|c|c|c|c|c|}
\hline Structure & $A\left(\mathrm{~m}^{2}\right)$ & Material & $\rho\left(\mathrm{kg} / \mathrm{m}^{3}\right)$ & $E(\mathrm{~Pa})$ & $\mu$ \\
\hline \multirow{2}{*}{ Girder } & $2.679 \times 10^{0}$ (suspension cables) & Steel & 7850 & $2.1 \times 10^{11}$ & 0.3 \\
\hline & $2.935 \times 10^{0}$ (the rest) & Steel & 7850 & $2.1 \times 10^{11}$ & 0.3 \\
\hline \multirow[b]{2}{*}{ Cross-girder } & $3.588 \times 10^{-1}$ (suspension cables) & Steel & 7850 & $2.1 \times 10^{11}$ & 0.3 \\
\hline & $5.194 \times 10^{-1}$ (the rest) & Steel & 7850 & $2.1 \times 10^{11}$ & 0.3 \\
\hline \multirow{3}{*}{ Tower } & $(5.489-8.684) \times 10^{1}$ (upper tower) & Concrete & 2500 & $3.65 \times 10^{10}$ & 0.167 \\
\hline & $(3.254-3.535) \times 10^{1}$ (middle tower) & Concrete & 2500 & $3.65 \times 10^{10}$ & 0.167 \\
\hline & $(3.608-4.319) \times 10^{1}$ (lower tower) & Concrete & 2500 & $3.65 \times 10^{10}$ & 0.167 \\
\hline Main cables & $4.230 \times 10^{-1}$ & Hot-dip galvanized steel wire & 8400 & $1.95 \times 10^{11}$ & 0.3 \\
\hline Stay cables & $(8.582-19.204) \times 10^{-3}$ & Hot-dip galvanized steel wire & 8400 & $1.95 \times 10^{11}$ & 0.3 \\
\hline Suspension cables & $8.851 \times 10^{-3}$ & Hot-dip galvanized steel wire & 8400 & $1.95 \times 10^{11}$ & 0.3 \\
\hline
\end{tabular}

coordinate system of the finite element model, the transverse bridge direction is taken as the $X$-axis, the vertical direction as the $Y$-axis, and the longitudinal direction as the $Z$-axis. The middle span of the girder is taken as the origin of coordinates, and the two bridge towers are at $Z= \pm 744 \mathrm{~m}$.

In this paper, BEM refers to the finite element model based on the beam element that is established by the traditional modelling method. IBEM refers to the finite element model of the girder based on the BEAM44 element (the girder stiffness has not been corrected). RM refers to the finite element model of the girder based on the SHELL181 element. CBEM refers to the corrected IBEM; that is, the finite element model after stiffness of the girder has been corrected. Modelling differences are shown in Table 2.

After the BEM and RM are established, to make sure that the two have the same mass is a prerequisite for comparing the static and dynamic characteristics. Figure 5 shows the comparison of accumulated mass and segmental mass of the two girders in the longitudinal direction in the finished state. The relative error of the total mass of the two girders is $0.0012 \%$, and the maximum relative error of segmental mass is $0.06 \%$.

\subsection{Fundamental Frequency Differences in the Finished State.} The RM has a better performance in simulating the mechanical properties of the bridge girder, but the IBEM may not be able to simulate it accurately. After the comparison of the mass in the two models is made, the modal analysis of the IBEM and the RM is to be carried out. The finite element software ANSYS provides many modal analysis methods. This paper adopts the Block Lanczos method, which is applied to deal with the mass matrix and stiffness matrix in large symmetrical structures and has fast convergence. Fundamental frequency of both models is comparatively shown in Figure 6.

According to Figure 6, the IBEM cannot virtually simulate the diaphragms and cross-beams of the girder and has a large relative error compared with the calculated value of the $\mathrm{RM}$, in which the relative error of torsional fundamental frequency is $-17.43 \%$, and the relative error of transverse bending fundamental frequency is $-20.14 \%$. Apparently, the discrepancy cannot be ignored. However, since the vertical bending stiffness of the bridge system is mainly provided by cables rather than the girder, its relative error is expected to
TABLE 2: Modelling differences.

\begin{tabular}{lcccc}
\hline Structure & BEM & IBEM & RM & CBEM \\
\hline Girder & BEAM44 & BEAM44 & SHELL181 & BEAM44 \\
Tower & BEAM44 & BEAM44 & SOLID185 & BEAM44 \\
Cables & LINK10 & LINK10 & LINK10 & LINK10 \\
\hline
\end{tabular}

be small. Just as Figure 6 shows, the relative error of vertical bending fundamental frequency is only $+2.47 \%$, which can be ignored.

Although more accurate results can be obtained by simulating the mechanical properties of bridges based on a $\mathrm{RM}$, due to the laborious modelling workload, long computing time, and high requirements for computer configuration, it is difficult to limit the cost in engineering design. Moreover, the number of meshes of the model in this paper exceeds 5 million, so it is hard to employ the refined bridge model at the current stage for a dynamic analysis. A more realistic approach is still to model the bridge by using the $\mathrm{BEM}$, and to use simulation results of the RM as the reference value to correct the IBEM to achieve equivalence between the two in terms of static and dynamic properties and then analyze dynamic behavior of the CBEM to achieve accuracy and efficiency when simulating.

\section{Correction of Torsional Stiffness of the IBEM}

5.1. Model Correction Method. There are significant differences in mechanical properties between the IBEM and the RM. The IBEM should be corrected by the model correction method, which, in essence, is to optimize related parameters. The optimization method adopted in this paper is the artificial bee colony (ABC) algorithm, which is a new intelligent optimization algorithm produced by bees' nectar gathering behavior in nature. At present, it has been successfully applied in engineering optimization [24-27]. Its principle refers to the mechanism of bees finding the best nectar source and creating data flows around the beehive by roaming, which is a behavior of bees that constitutes the basics of the swarm intelligence [28].

There are three types of bees: employed, onlooker, and scouts. Each species plays a different role in the optimization process. The employed bees stay above the nectar source and keep the neighboring nectar source in mind. Onlooker bees 


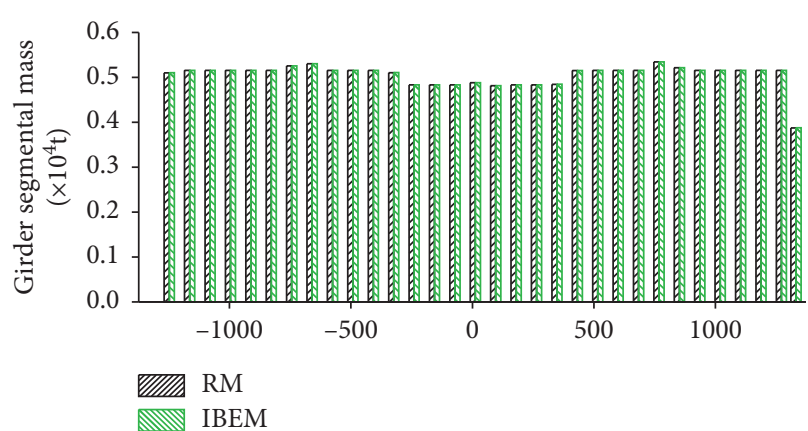

(a)

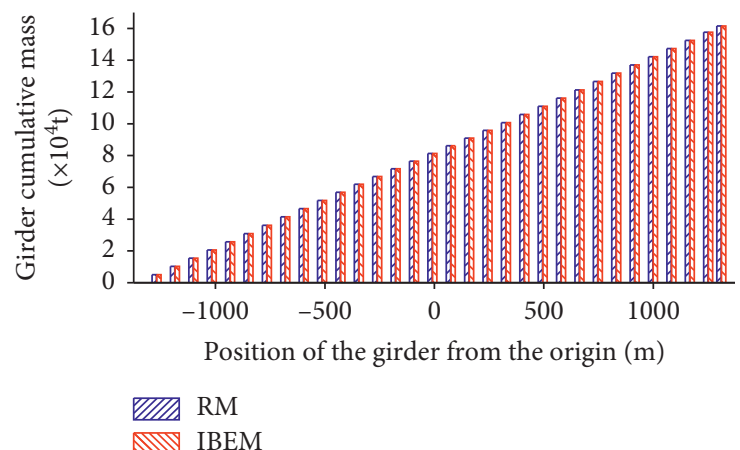

(b)

FIGURE 5: Girder quality comparison diagram.

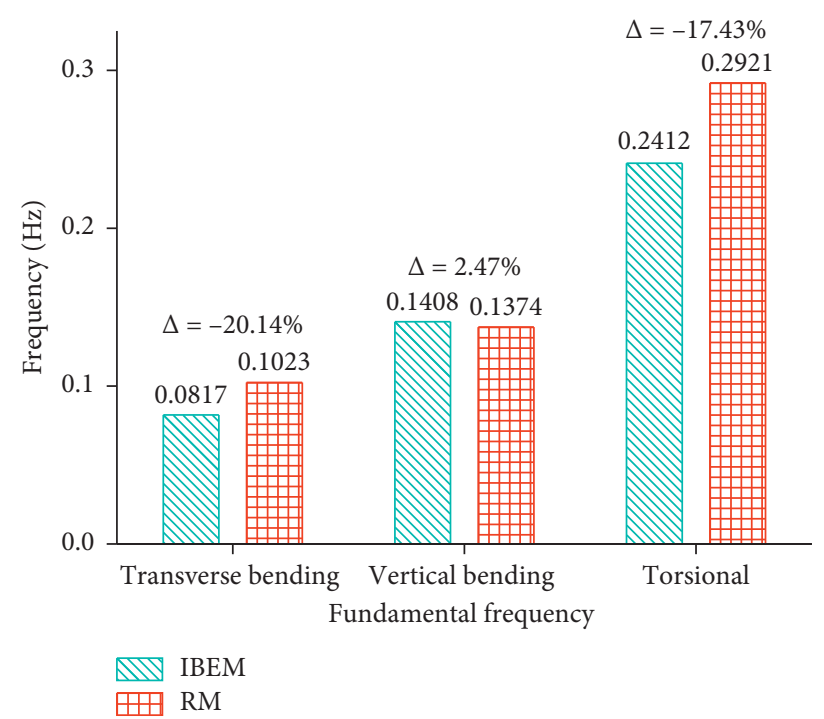

FIGURE 6: Fundamental frequency difference of the finished state. And $\Delta=$ calculation value of IBEM-calculation value of $\mathrm{RM} /$ calculation value of $\mathrm{RM} \times 100 \%$.

get information from employed bees and make a resource choice to collect the nectar. In addition, the scouts are responsible for calculation. The algorithm consists of three steps:

First, the employed bees are sent to scamper for resources, and the nectar amount here is the employed bees, and the nectar amount is calculated.

Secondly, the onlooker bees make a resource choice in accordance with the information they took from finding new nectar resources.

Finally, one of the employed bees is nominated randomly as a scout bee, and it is sent to the sources to find new sources [29-31].

Half of the bees in the colony are appointed as employed, and the rest as onlooker bees in this optimization algorithm. Therefore, the number of employed bees is equal to the number of nectar sources, and the food source in the algorithm refers to the possible solutions of the problem to be optimized. The amount of nectar from a source means the quality of the source. Less nectar means poor optimization effect, while more nectar means better optimization effect. Synthesize the above-mentioned steps and continue the cycle until the best nectar source is found.

Figure 7 shows the process of applying $\mathrm{ABC}$ algorithm to correct the IBEM. Before correction, the dynamic characteristics of the RM and the torsion angle of the girder under aerostatic load should be calculated. Then, the results are seen as reference values to construct an objective function, as shown in the following formula:

$$
W=\sum_{i}\left(f_{i}-f_{i}^{\prime}\right)^{2}+\sum_{j}\left(\theta_{j}-\theta_{j}^{\prime}\right)^{2}
$$

where $f_{i}$ is the frequency of the RM, $f_{i}^{\prime}$ is the frequency of the BEM, $\theta_{j}$ is the torsion angle of the girder of the RM, and $\theta_{j}^{\prime}$ is the torsion angle of the girder of the BEM.

According to the $0^{\circ}$ three-component coefficient in the finished state and the construction states obtained from the segmental model wind tunnel test, the aerostatic moment is calculated through formula (8), and then the torsion angle of 


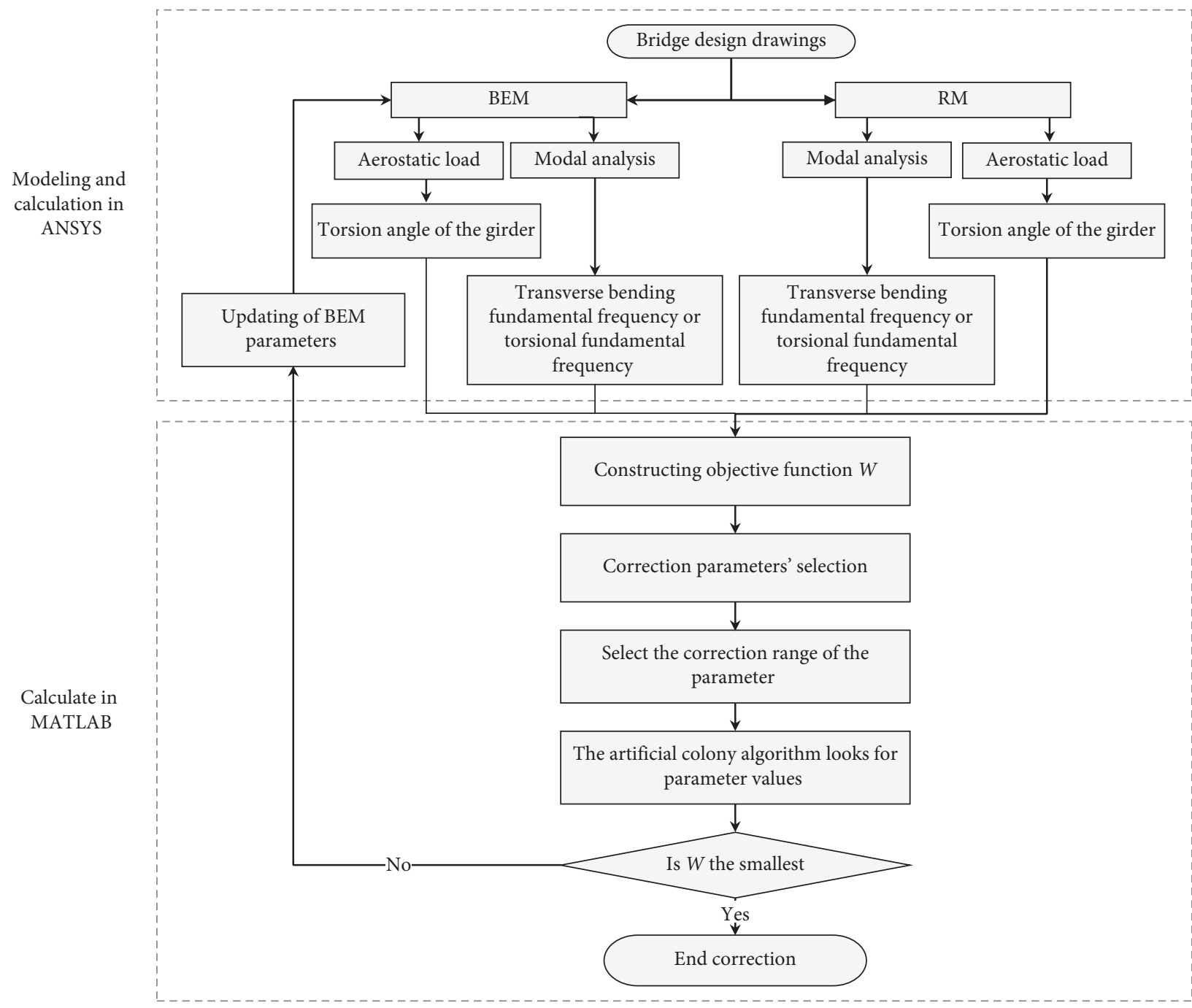

Figure 7: Model correction flowchart.

the girder of the bridge finite element model under the aerostatic moment is obtained.

$$
M_{T}=\frac{1}{2} \rho U^{2} C_{M} B^{2}
$$

where $\rho$ is the air density that takes $1.25 \mathrm{~kg} / \mathrm{m}^{3}, U$ is the wind speed of inflow $(66.6 \mathrm{~m} / \mathrm{s}$ is taken in the finished state and $61.3 \mathrm{~m} / \mathrm{s}$ in the construction states), $C_{M}$ is the moment coefficient $(-0.03$ is taken in the finished state and 0.023 in the construction states), and $B$ is the cross-section width of the girder which takes $68 \mathrm{~m}$.

Thus, it is calculated that the loading moment of each section is $-5383882.73 \mathrm{~N} \cdot \mathrm{m}$ in the finished state, and the loading moment of each section is $3496831.16 \mathrm{~N} \cdot \mathrm{m}$ in the construction states. 191 points are loaded here in total. In another words, a loading point is set on the cross section of the girder at every cross-beam.

Then, it is necessary to select the correction parameters of the BEM and specify the correction range of the parameters. As the relative errors in the mechanical properties of the IBEM and the RM are caused by the diaphragms and the cross-beams, $\beta_{1}$ and $\beta_{2}$ are selected as correction parameters, in which $\beta_{1}$ refers to the growth factor of the girder transverse bending moment of inertia and $\beta_{2}$ the growth factor of torsional moment of inertia. Here, if we directly increase the transverse bending moment of inertia to improve the transverse bending stiffness [32], we will indirectly reduce the torsional fundamental frequency, which in turn makes the torsional stiffness correction parameter large. In this paper, the following measure is taken: the mass of the girder is set to 0 , and its mass and mass moment of inertia are simulated with MASS21 element. According to the structural characteristics and practical experience, the range of correction parameters is $[1,10]$. In the process of correction, the value of $\beta_{1}$ or $\beta_{2}$ varies randomly within a specified range, and the torsional rigidity of the BEM or transverse bending stiffness is increased to some extent. Then, the torsion angle or fundamental frequency of the girder of the BEM with increased stiffness is calculated and compared with the corresponding reference value. The optimization range specified in this paper is less than 
$5 \%$. Finally, the ABC algorithm program is executed in MATLAB to find the optimal solution of the objective function.

5.2. Comparison of Aerostatic Responses. Under the strong wind, the girder of the bridge would undergo elastic torsion or flexural deformation [33]. When the additional aerodynamic force caused by the deformation of the girder exceeds the increment of the resistance capacity of the bridge structure itself, the deformation of the girder would be exacerbated, which makes the girder unstable, namely, the aerostatic instability of the girder. Under the circumstances that the aerodynamic structure of the girder is determined, the critical wind speed of aerostatic instability of the girder is determined by the torsional stiffness of the girder [34]. It is necessary to simulate the torsional stiffness of the girder structure as accurately as possible when the BEM is applied.

In terms of the aerostatic responses of the bridge in this paper at the design wind speed, the calculation results of the IBEM/CBEM and the RM are shown in Figure 8. As per Figure 8, the torsion angle of the girder of the CBEM is extremely close to that of the RM. The relative error between the torsion angle of the girder end of the IBEM and the corresponding reference value in the common doublecantilever state is decreased from $+17.40 \%$ to $-0.30 \%$. The relative error between the torsion angle of the girder end of the IBEM and the corresponding reference value in the maximum double-cantilever state is decreased from $+17.67 \%$ to $-1.62 \%$. The relative error between the torsion angle of the girder in the middle span of the IBEM and the corresponding reference value in the preclosure states is decreased from $+61.28 \%$ to $+3.08 \%$. The relative error between the torsion angle of the girder in the middle span of the IBEM and the corresponding reference value in the finished state is decreased from $+61.71 \%$ to $+4.94 \%$.

The calculation results show that the torsion angle of the girder of the IBEM is quite different from the reference value, and its torsional stiffness simulation is distorted, which fails to accurately simulate the torsional stiffness of the girder. The torsion angle of the girder of the CBEM is closer to that of the RM, and the CBEM can quickly and accurately simulate the aerostatic responses of the girder, thereby improving the efficiency of related projects.

5.3. Comparison of Dynamic Characteristics. Dynamic characteristics of bridges include natural frequency and mode shape, which are the basis of calculating the critical wind speeds of aerostatic instability and flutter [35]. The accurate calculation of dynamic characteristics of the bridge structure is based on the accurate simulation of torsional stiffness of the bridge girder.

Transverse bending fundamental frequency and torsion fundamental frequency of the IBEM/CBEM and the RM are comparatively shown in Figure 9. As per Figure 9, the torsional fundamental frequency of the girder of the CBEM in each state during the construction stages is extremely close to the corresponding reference value, and the transverse bending fundamental frequency and torsional fundamental frequency of the CBEM in the finished state are close to the corresponding reference value. In more details, the relative error between the torsional fundamental frequency of the IBEM and the corresponding reference value in the common double-cantilever state is decreased from $-7.10 \%$ to $+1.56 \%$. The relative error between the torsional fundamental frequency of the IBEM and the corresponding reference value in the maximum double-cantilever state is decreased from $-9.68 \%$ to $+0.62 \%$. The relative error between the torsional fundamental frequency of the IBEM and the corresponding reference value in the preclosure states is decreased from $-3.23 \%$ to $+1.14 \%$. The relative error between the torsional fundamental frequency of the IBEM and the corresponding reference value in the finished state is decreased from $-17.43 \%$ to $+3.66 \%$, and the relative error between the transverse bending fundamental frequency and the corresponding reference value is decreased from $-20.14 \%$ to $-0.39 \%$.

The finite element models in this paper are established according to the design drawings and relevant parameters and are also under constraints as per the actual structure. The basic frequency is calculated by ANSYS. Jiangyin Yangtze River Bridge [36] is a suspension bridge with a main span of $1385 \mathrm{~m}$. The length of the main span is similar to that of the bridge mentioned in this paper. The girder is a singlebox steel one, which has a $0.0536 \mathrm{~Hz}$ first-order symmetric transverse bending frequency, and a $0.2811 \mathrm{~Hz}$ first-order symmetric torsional frequency. The values are similar to those of the RM calculated in this paper. Since the forms of the girders are different, there are some nuances between the values. It can be seen that the fundamental frequency in this paper is valid and reasonable.

The relative error between the torsional fundamental frequency and the corresponding reference value gradually augments with the increase in the length of girder of the IBEM, which indicates that if the IBEM is directly employed to simulate the construction stages, the deviation between the predicted torsional stiffness of the girder and the real situation may become increasingly larger.

The frequencies of the mode shape at the first 30 orders of the RM in the finished state are in the range of $0.1 \mathrm{~Hz}-0.38 \mathrm{~Hz}$. The maximum relative error between the IBEM and the corresponding mode of the RM is up to $20.14 \%$. The fundamental frequency of the CBEM is very close to the calculated values of the RM. The relative errors of the other orders are reduced, and the maximum is only $11.86 \%$, which means that the CBEM has high calculation accuracy. The CBEM can analyze in a fast and accurate manner in many aspects, such as buffeting responses prediction, seismic responses analysis, and parameter sensitivity study.

Based on the RM of three typical construction states and one finished state, 4 groups of corrected parameters are obtained as shown in Table 3. As per Table 3, the transverse bending fundamental frequency of the IBEMs in the construction stages is relatively close to that of the RM, in which the relative error between the transverse bending fundamental frequency and the corresponding reference value in the common double-cantilever state is only $-1.84 \%$, and the 


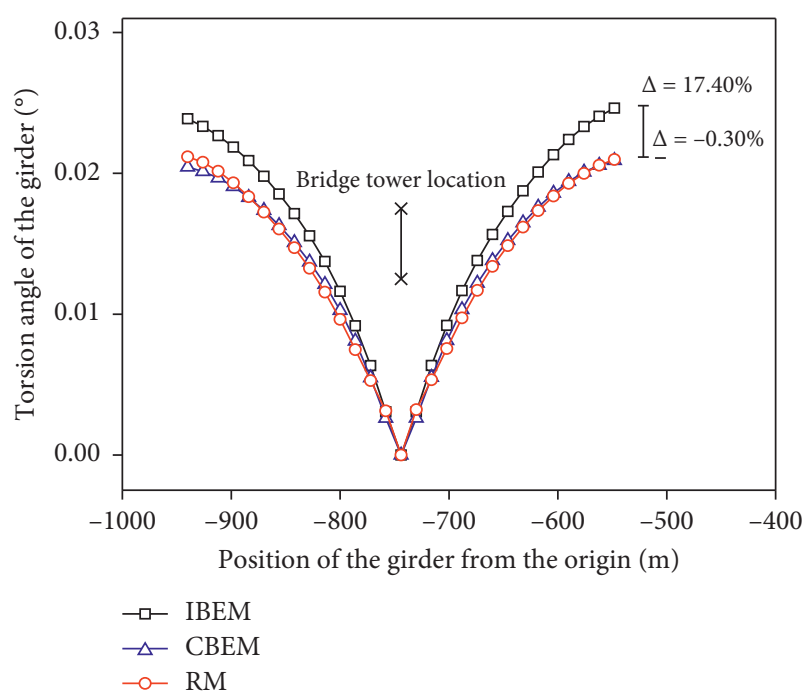

(a)

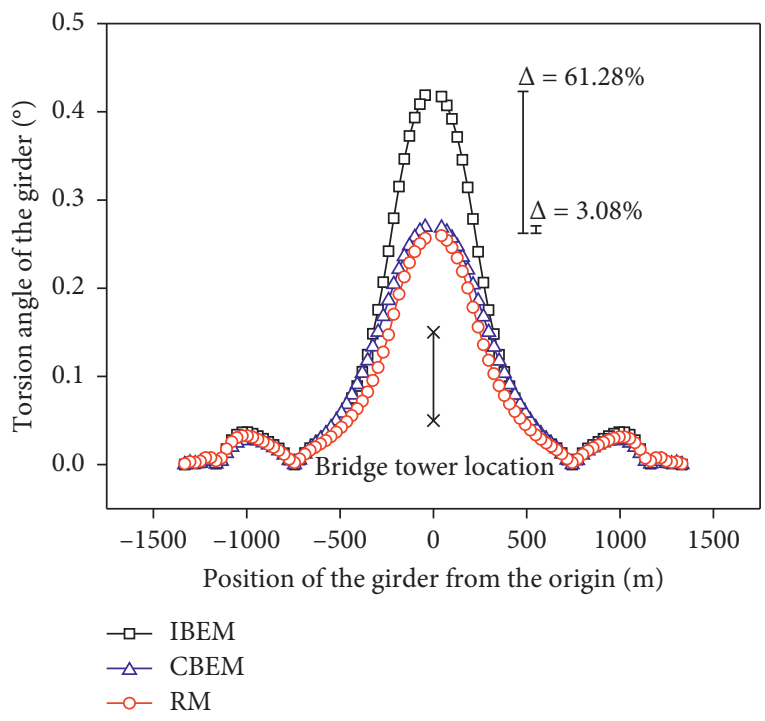

(c)

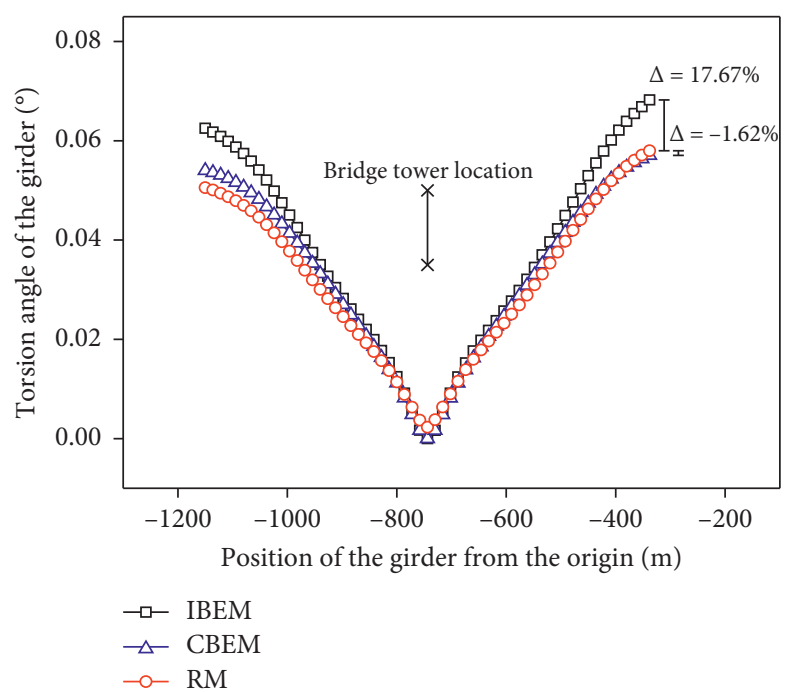

(b)

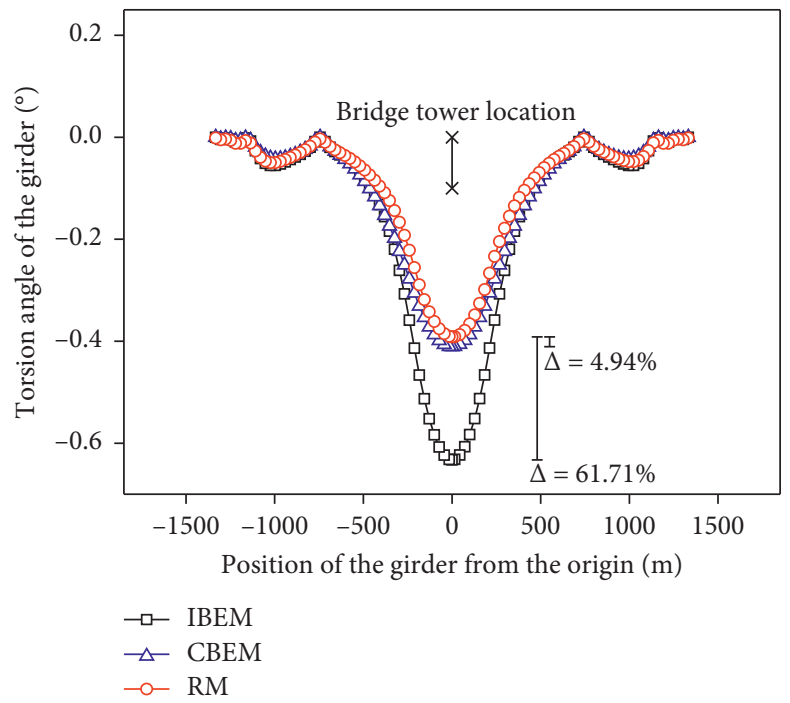

(d)

Figure 8: Comparison diagram of torsional angle of the girder in different states. (a) The common double-cantilever state. (b) The maximum double-cantilever state. (c) The preclosure states. (d) The finished state. And $\Delta=$ (calculation value of IBEM(CBEM) calculation value of $\mathrm{RM} /$ calculation value of $\mathrm{RM}) \times 100 \%$.

relative error between the transverse bending fundamental frequency and the corresponding reference value in the preclosure states is only $-2.56 \%$. So the transverse bending stiffness of the IBEMs in the construction stages has not been corrected. Meanwhile, the girder torsional stiffness correction parameter in Table 3 is 2.8 for all IBEMs in different bridge states. On the one hand, it shows that the IBEM, modelled directly according to the conventional method, is unable to accurately simulate the diaphragms and crossbeams, because, in that way, it will result in a remarkable underestimation of the torsional stiffness of the girder. On the other hand, it also shows that if the IBEM is used to simulate the finished state, it is only needed to build a RM in the common double-cantilever state to find the girder torsional stiffness correction parameter and apply it into the
IBEM in the finished state, which can quickly correct the torsional stiffness of the girder of the IBEM in the finished state and calculate the torsional fundamental frequency of bridge more accurately, thus improving the efficiency of obtaining effective data in the bridge engineering design stages.

Based on reference value of the RM in the finished state, the correction parameter of transverse bending fundamental frequency of the IBEM in the finished state is 10. It should be noted that the triple-girder model established in this paper is fundamentally different from the triple-girder model established in reference [1], in which the cross section of the girder is artificially divided into three parts to establish a virtual triple-girder model, and the transverse bending moment of inertia of the cross 


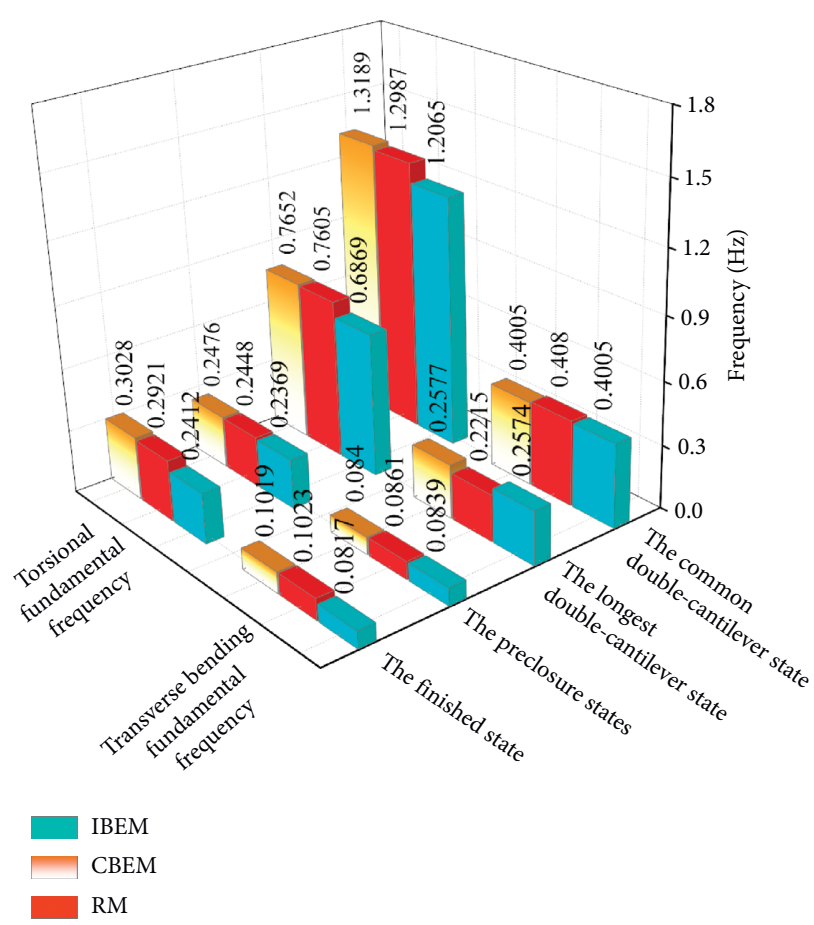

Figure 9: Fundamental frequency comparison in different stages.

TABLE 3: Correction parameters in different states.

\begin{tabular}{lcr}
\hline Different states & Correction parameters \\
& $\beta_{1}$ & $\beta_{2}$ \\
\hline The common double-cantilever state & 1 & 2.8 \\
The longest double-cantilever state & 1 & 2.8 \\
The preclosure states & 1 & 2.8 \\
The finished state & 10 & 2.8 \\
\hline
\end{tabular}

section of the girder is concentrated in the middle girder to ensure that the transverse stiffness turns out to be the same. The triple-girder model established in this paper is an objectively existing STSBG, and three longitudinal girders are established at the centre axis of each of the three boxes according to their real cross-sectional properties. During the process, the cross-sectional properties of the girder are not artificially assigned. The correction parameter is a little larger after the model correction. In fact, in view of the different modelling approaches, the transverse bending stiffness correction parameter in this paper does not necessarily increase the overall stiffness of the STSBG by a factor of 10 .

The analysis of all models in this paper is carried out on the same computing platform with a $3.6 \mathrm{GHz} \mathrm{CPU}$ and a 96 GB RAM. IBEM/CBEM in the finished stage includes 2809 nodes and 4159 elements. It takes only 5 seconds to calculate dead load of the bridge in the geometric nonlinearity and the subsequent dynamic characteristics of the bridge at the first 30 orders. $\mathrm{RM}$ in the finished state includes 5,029,138 nodes and 5,953,325 elements. The computing time would decrease with the increase in the capacity of RAM. More details are given in Figure 10. At

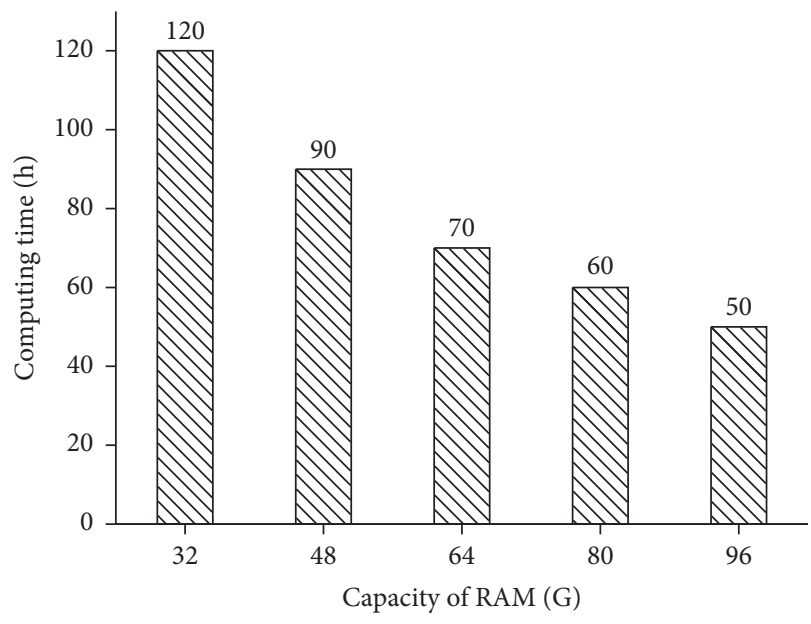

Figure 10: The RM computing time variations.

the bridge design stage, the computing time can be estimated according to the number of model elements and the capacity of RAM. If necessary, it is considered to increase the capacity of RAM to improve working efficiency. 


\section{Conclusions}

This paper mainly studies the differences of torsional stiffness of STSBG under different modelling methods, and ABC algorithm is employed to correct IBEM parameters. The static/dynamic characteristics of IBEM, CBEN, and RM are compared to evaluate the effectiveness of the model correction. The following conclusions can be drawn based on the obtained results:

(1) For the bridge with a STSBG as the girder, the IBEM established directly by the conventional method may be distorted when simulating the torsional stiffness of the structure. The relative error between the torsional fundamental frequency of the IBEM and the corresponding reference value in the finished state is $-17.43 \%$, and the relative error of transverse bending fundamental frequency is $-20.14 \%$.

(2) The torsion angle of the girder of the IBEM is quite different from the corresponding reference values. The relative errors between the calculated values of IBEM and the corresponding reference values are $+17.40 \%,+17.67 \%,+61.28 \%$, and $+61.71 \%$ in the common double-cantilever state, the longest doublecantilever state, the preclosure states, and the finished state, respectively.

(3) Based on the objective function constructed by calculation values in the RM, the optimal correction parameters can be found out quickly through the $A B C$ algorithm, which improves the simulation accuracy of the torsional stiffness and transverse bending stiffness of the IBEM in the finished state to a greater extent, and the subsequent calculation can be conducted fast and more accurately by application. The CBEM, as a substitute for RM, can make a faster and more accurate calculation for the following steps.

(4) The correction parameters of the torsional stiffness of the girder of the IBEMs in the typical construction stages and the finished state are the same, namely, 2.8. In view of this girder structure, a common double-cantilever RM with a few meshes is only needed to be modelled for rapid correction of the torsional stiffness of IBEM in the finished state, which takes only about two hours for computing. In this way, the fast and accurate calculation of torsional fundamental frequency can be achieved, and the bending-torsion frequency ratio can be calculated correctly, thus analyzing the flutter stability more accurately in the bridge engineering design.

(5) The number of meshes in the RM established in this paper is more than 5 million, and its computing efficiency is mainly determined by the hardware configuration of the computer. Through calculation and analysis, when the frequency of the CPU is given, the higher capacity a RAM has, the more efficient it will be. To improve work efficiency, the capacity of RAM of the computer can be appropriately increased according to needs.
It is noted that the stiffness of the girder also has a significant influence on bridges' critical wind speeds of aerostatic instability and flutter. Further efforts are still needed on this topic by the authors.

\section{Data Availability}

The simulation data used to support the findings of this study are included within the article.

\section{Conflicts of Interest}

The authors declare that there are no conflicts of interest regarding the publication of this paper.

\section{Acknowledgments}

The authors gratefully acknowledge the support for the research work jointly provided by the National Natural Science Foundation of China (no. 51808470) and the Scientific Research Project of Education Department of Hunan Province (no. 18K012).

\section{References}

[1] H. F. Xiang and L. D. Zhu, "Dynamic analysis model of cablestayed bridge considering the influence of torsional stiffness," in Proceedings (Volume II) of the National Bridge Structure Academic Conference, Shanghai, China, November 1992.

[2] L. Kang, Q. L. Zhang, Z. Q. Wang, and J. Wu, "Numerical method of free torsion constant for arbitrary complicated thin-walled cross section," Journal of Central South University, vol. 42, no. 5, pp. 1437-1441, 2011.

[3] R. K. Dowell and T. P. Johnson, "Closed-form shear flow solution for box-girder bridges under torsion," Engineering Structures, vol. 34, pp. 383-390, 2012.

[4] X. L. Xu, S. G. Wang, W. Q. Liu, and S. Y. Li, "Simplified calculation method for torsion parameters of thin-walled box girder section," China Journal of Highway and Transport, vol. 20, no. 2, pp. 72-76, 2007.

[5] Z. T. Zhang and Y. J. Ge, "Static and dynamic analysis of suspension bridges based on an orthotropic shell finite element method," Structural Engineers, vol. 19, no. 4, pp. 21-25, 2003.

[6] X. Y. Chen, "Research on torsion rigidity of steel box girder of orthotropic bridge deck," Highway, vol. 55, no. 5, pp. 54-56, 2010.

[7] Y. J. Ge, B. S. Du, and H. F. Xiang, "Structure dynamic analysis models of super-long-span suspension bridges," Engineering Mechanics, vol. S3, pp. 36-40, 2004.

[8] F. Nieto, S. Hernández, and J. Á. Jurado, "Optimum design of long-span suspension bridges considering aeroelastic and kinematic constraints," Structural and Multidisciplinary Optimization, vol. 39, no. 2, pp. 133-151, 2009.

[9] M. Li, Research on the Calculation Model of Separate Steel Box Stiffening Girder, Southwest Jiaotong University, Chengdu, China, 2009.

[10] Y. L. Li, G. Y. Hou, C. J. Li, and S. Z. Qiang, "Flutter stability of a super-long-span suspension bridge with CFRP main cables during erection," Journal of Vibration and Shock, vol. 31, no. 21 , pp. 15-21, 2012. 
[11] T. Tao, H. Wang, and Y. Gao, "Parametric analysis on flutter performance of a long-span quadruple-tower suspension bridge," Structure, vol. 28, no. 1, pp. 1108-1118, 2020.

[12] H. Wang, Z. Xu, M. Yang, T. Tao, J. Mao, and H. Gao, "Numerical analysis on buffeting performance of a long-span four-tower suspension bridge using the FEM model," KSCE Journal of Civil Engineering, vol. 25, no. 3, pp. 854-865, 2021.

[13] H. Wang, T. Tao, R. Zhou, X. Hua, and A. Kareem, "Parameter sensitivity study on flutter stability of a long-span triple-tower suspension bridge," Journal of Wind Engineering and Industrial Aerodynamics, vol. 128, pp. 12-21, 2014.

[14] M. R. Awall, T. Hayashikawa, T. Matsumoto, and X. He, "Effects of bottom bracings on torsional dynamic characteristics of horizontally curved twin I-girder bridges with different curvatures," Earthquake Engineering and Engineering Vibration, vol. 11, no. 2, pp. 149-162, 2012.

[15] N. A. Nariman, "A novel structural modification to eliminate the early coupling between bending and torsional mode shapes in a cable stayed bridge," Frontiers of Structural and Civil Engineering, vol. 11, no. 2, pp. 131-142, 2017.

[16] D. Wang, Y. Deng, and Y. Liu, "Influence of central buckle on suspension bridge dynamic characteristics and driving comfort," Journal of Central South University, vol. 22, no. 8, pp. 3108-3115, 2015.

[17] S. Farahmand-Tabar and M. Barghian, "Formulating the optimum parameters of modified hanger system in the cablearch bridge to restrain force fluctuation and overstressing problems," Journal of the Brazilian Society of Mechanical Sciences and Engineering, vol. 42, no. 9, p. 453, 2020.

[18] S. Farahmand-Tabar and M. Barghian, "Response control of cable-stayed arch bridge using modified hanger system," Journal of Vibration and Control, vol. 26, no. 23-24, pp. 2316-2328, 2020.

[19] T. Yoshimura and M. Kawahara, "Aerodynamic stability of large suspension bridge using cable frames," Iabse Symposium Report, vol. 97, no. 35, pp. 17-24, 2010.

[20] S. Farahmand-Tabar and M. Barghian, "Seismic assessment of a cable-stayed arch bridge under three-component orthotropic earthquake excitation," Advances in Structural Engineering, vol. 24, no. 2, pp. 227-242, 2020.

[21] Z. T. Zhang, Z. Q. Chen, X. G. Hua, C. G. Li, and Y. J. Ge, "Investigation of turbulence effects on torsional divergence of long-span bridges by using dynamic finite-element method," Journal of Bridge Engineering, vol. 15, no. 6, pp. 639-652, 2010.

[22] K. F. Zheng, J. S. Tang, and Y. L. Wang, "3-D structural analysis method based on all shell elements of steel bridge," Journal of Railway Engineering Society, vol. 2, pp. 17-22, 1997.

[23] X. F. Sun, X. S. Fang, and L. T. Guan, Mechanics of Materials, Higher Education Press, Beijing, China, 2009.

[24] Y. Lin, Z. Q. Feng, X. G. Hua, and Z. Q. Chen, “Artificial bee colony algorithm for flutter derivatives identification of bridge decks using free vibration records," Engineering Mechanics, vol. 37, no. 2, pp. 192-200, 2020.

[25] M. A. Latif and M. P. Saka, "Optimum design of tied-arch bridges under code requirements using enhanced artificial bee colony algorithm," Advances in Engineering Software, vol. 135, Article ID 102685, 2019.

[26] H. Liu, X. He, Y. Jiao, and X. Wang, "Reliability assessment of deflection limit state of a simply supported bridge using vibration data and dynamic bayesian network inference," Sensors, vol. 19, no. 4, p. 837, 2019.

[27] J. Yang and Z. Peng, "Improved ABC algorithm optimizing the bridge sensor placement," Sensors, vol. 18, no. 7, p. 2240, 2018.
[28] A. Ozturk, S. Cobanli, P. Erdogmus, and S. Tosun, "Reactive power optimization with artificial bee colony algorithm," Scientific Research and Essays, vol. 5, no. 19, pp. 2848-2857, 2010.

[29] D. Karaboga and B. Basturk, "A powerful and efficient algorithm for numerical function optimization: artificial bee colony (ABC) algorithm," Journal of Global Optimization, vol. 39, no. 3, pp. 459-471, 2007.

[30] D. Karaboga and B. Basturk, "On the performance of artificial bee colony (ABC) algorithm," Applied Soft Computing, vol. 8, no. 1, pp. 687-697, 2008.

[31] F. Kang, J. J. Li, and Q. Xu, "Structural inverse analysis by hybrid simplex artificial bee colony algorithms," Computers \& Structures, vol. 87, no. 13-14, pp. 861-870, 2009.

[32] M. Yang, Study on Wind-Induced Flutter and Buffeting of a Long-Span Quadruple-tower Suspension Bridge Based on ANSYS, Southeast University, Nanjing, China, 2017.

[33] P. Hu, Y. Han, G. J. Xu, C. S. Cai, and W. Cheng, "Effects of inhomogeneous wind fields on the aerostatic stability of a long-span cable-stayed bridge located in a mountain-gorge terrain," Journal of Aerospace Engineering, vol. 33, no. 3, pp. 1-35, 2020.

[34] J. h. Luo, Z. Q. Chen, and G. D. Liu, "Research on instability mechanism of long-span cable-stayed bridges due to nonlinear aerostatic torsion," Engineering Mechanics, vol. 24, pp. 145-154, 2007.

[35] Z. Wang and E. Dragomirescu, "Flutter derivatives identification and aerodynamic performance of an optimized multibox bridge deck," Advances in Civil Engineering, vol. 2016, Article ID 8530154, 13 pages, 2016.

[36] J. M. W. Brownjohn, S.-K. Au, Y. Zhu et al., "Bayesian operational modal analysis of Jiangyin Yangtze River bridge," Mechanical Systems and Signal Processing, vol. 110, pp. 210-230, 2018. 